\title{
Correlation between endoscopic and histopathological findings in patients with stomach lesion referred to Firoozgar Hospital, Tehran (2016-2017)
}

\author{
G. Taheri ${ }^{1}$, GR. Hemmasi ${ }^{1}$
}

\begin{abstract}
${ }^{1}$ Gastrointestinal and Liver Disease Research Center, Iran University of Medical Sciences, Tehran, Iran
Corresponding Address: Gholam Reza Hemmasi, Gastrointestinal and Liver Disease Research Center, Iran University of Medical Sciences, Tehran, Iran. Tel: +98-21-88941831; Email: hemmasi46@yahoo.com Received: 4 Aug 2018; Accepted: 3 Oct 2018
\end{abstract}

\section{* Abstract}

Background: Stomach is a common location for benign and malignant lesions in the digestive system from inflammation to cancer. Therefore, recognition and diagnosis in the endoscopic stage and its confirmation in a pathological examination will be critical.

Objective: The aim of this study was to investigate the correlation between endoscopic and histopathological findings in the patients with stomach lesion.

Methods: In this cross-sectional study, 350 patients who referred to endoscopy center in Firoozgar Hospital were selected from 2016 to 2017. The stomach endoscopy was performed on various parts including; fundus, body (lesser and greater curvatures) and antrum, and pathological examination was performed on biopsy samples. The checklist was used to record patients' age and gender. Data were analyzed by t-test and Pearson correlation coefficient.

Findings: The mean age of patients was $51 \pm 6$ years and 207 patients $(59.1 \%)$ were male. The correlation between pathologic and endoscopic results for antrum, body and fundus were $0.62,0.56$ and 0.46 respectively. Also, the significant correlation between endoscopy and histopathology was found $(\mathrm{P}<0.001)$.

Conclusion: The results indicated that additional endoscopy reports and histopathological studies are required to achieve a better outcome for an accurate diagnosis. Also, the highest and lowest correlations between endoscopic and histopathological results were observed in the fundus and antrum, respectively.

Keywords: Endoscopy, Pathology, Stomach, Gastric fundus

Citation: Taheri G, Hemmasi GR. Correlation between endoscopic and histopathological findings in patients with stomach lesion referred to Firoozgar Hospital, Tehran (2016-2017). J Qazvin Univ Med Sci 2018; 22(5): 44-50. 


\title{
همخوانى يافتههاى آندوسكويى و هيستوياتولوزيكى بيويسى معده در بيماران ارجاعى به بيمارستان فيروز
}

\author{
دكتر كلمهر طاهرى'، دكتر غلامرضا حمصى'
}

' مركز تحقيقات بيمارى هاى كَوارش و كبد دانشَاه علوم يزشكى ايران، تهران، ايران

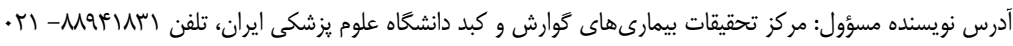

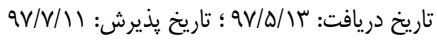

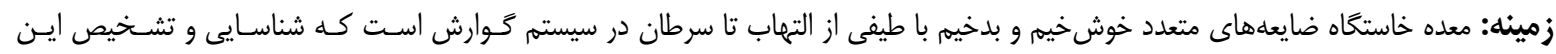

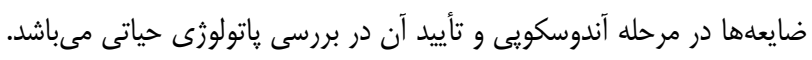

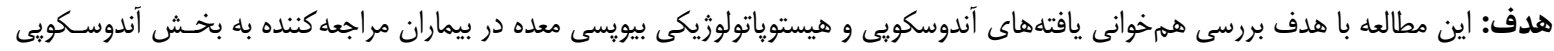

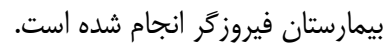

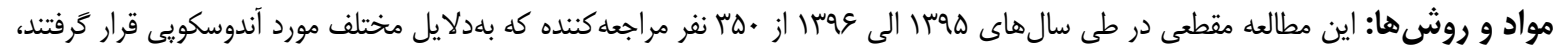

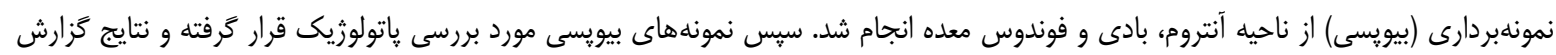

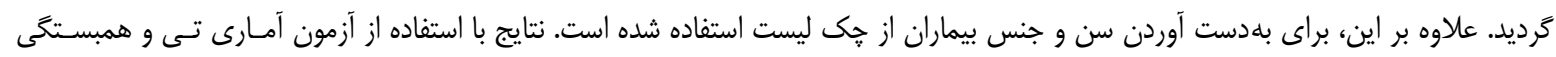

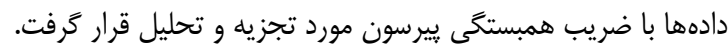

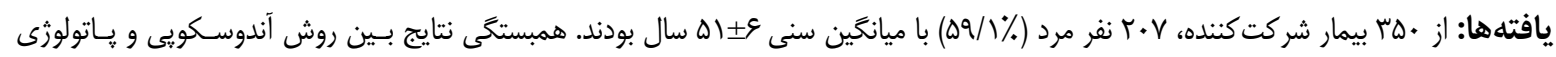

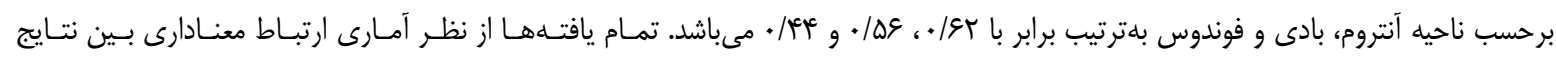

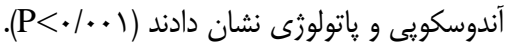

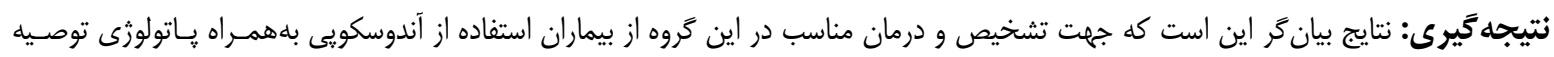

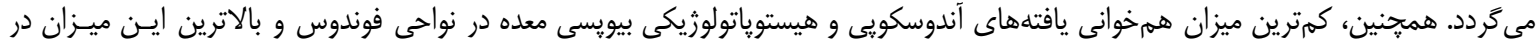
أنتروم مشخص كردين.

كليدوازَهها: آندوسكويى، ياتولوزى، معده، فوندوس معده

مقدمه

ايجاد اين بيمارى با اهميت در نظـر گرفتـه مسىشـوند.(T) روش هاى متنوعى براى غربال

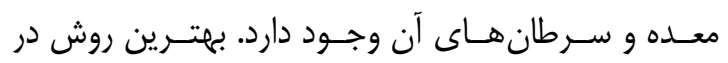

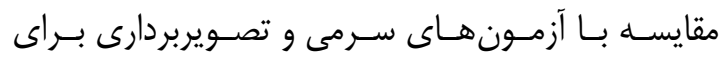
تشخيص زودهنكام مشكلات و سرطان معـده اسـتفاده از

$$
\text { آندوسكويى است.(") }
$$

طى آندوسكويى فوقانى، متخصصـين بيمـارىهـاى

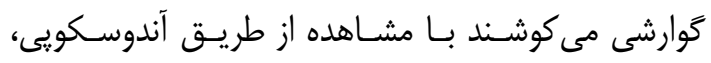

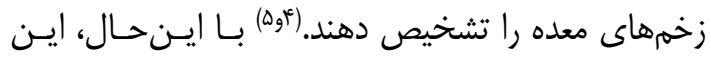

معده بلهعنوان محل مناسبى بـراى دامنـه وسـيعى از

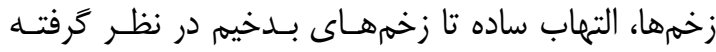

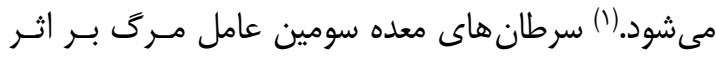

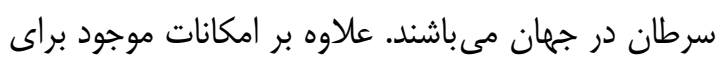

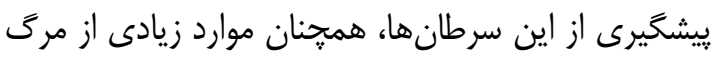

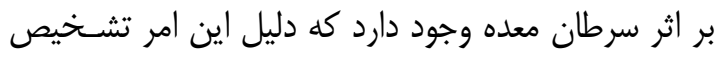
ديرهنگام اين بيمارى مى باشد. علاوه بر برخى عفونتهـا

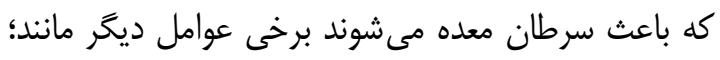

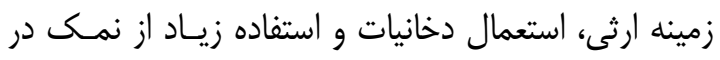




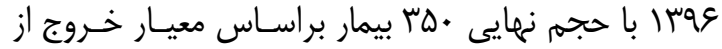

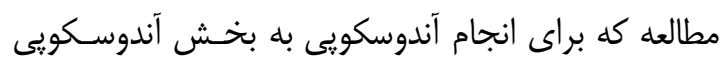

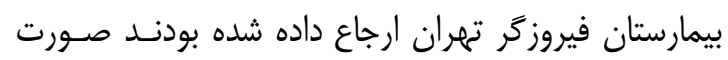

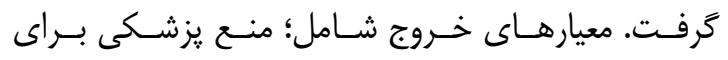
نمونهبردارى، تشخيص قطعى اخـتلال در بيمـاران، نيـاز

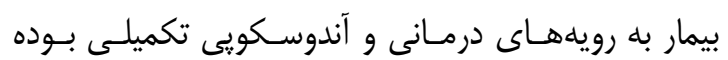
است. جهت انجام مطالعه از تمامى بيمـاران رضـايتنامـهـ

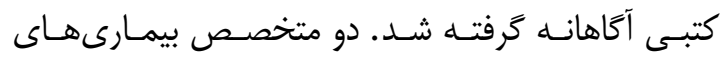
كوارشى آندوسـكويى فوقانى را بـر روى بيمـاران انجـام

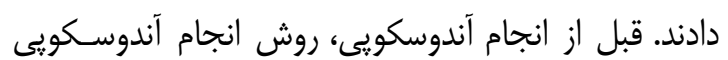

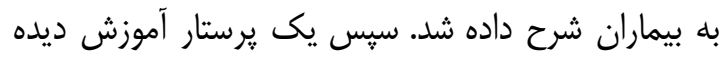

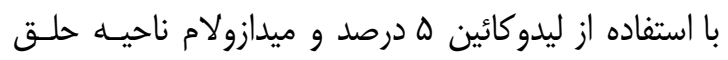

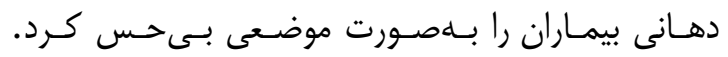

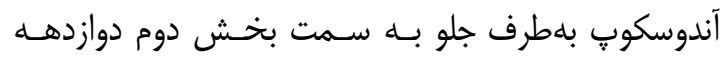

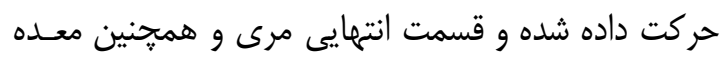

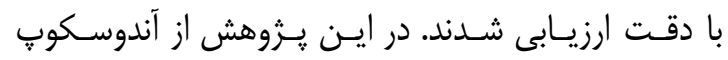
انعطافيذير "fujinon 2000" (ساخت زاين) استفاده شد.

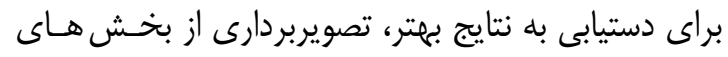

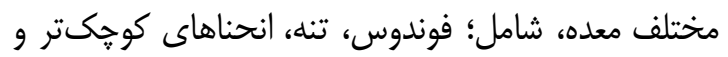

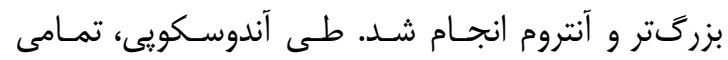

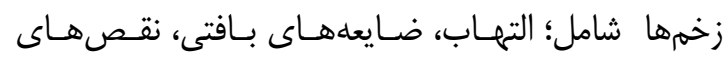

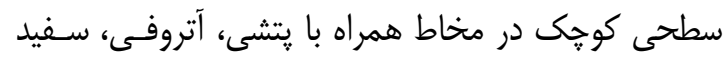

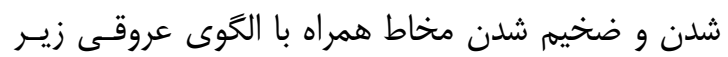

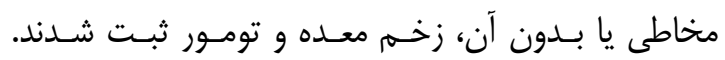

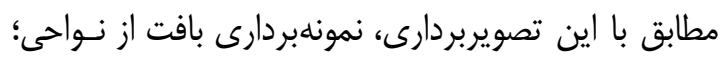

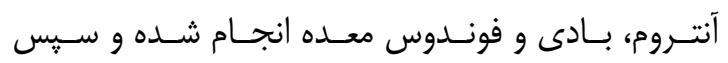

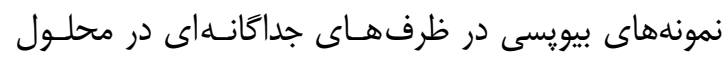
فرمالين به آزمايشگاه ارسال شدند.

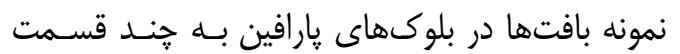

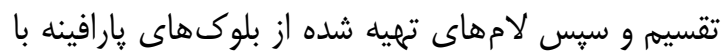

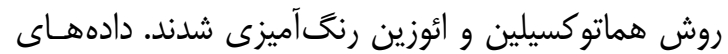

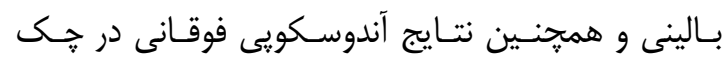

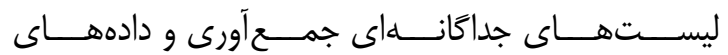

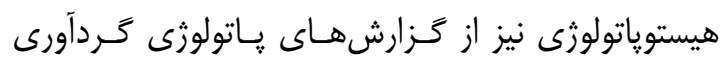

يرسش مطرح است كه آيا يافتههاى آندوسكويى با نتايج

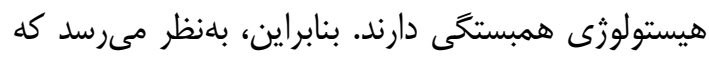

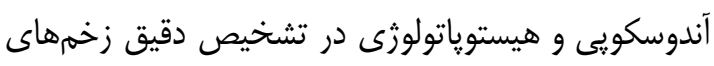

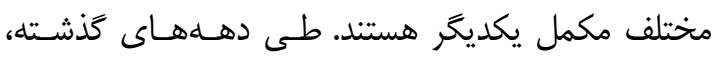

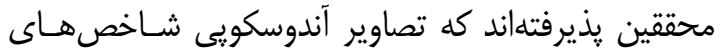

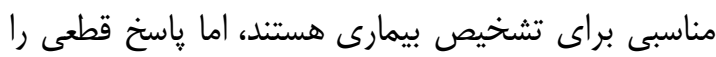

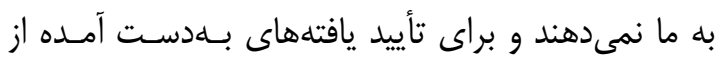

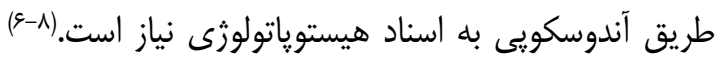

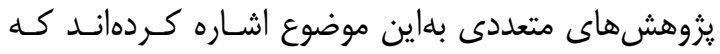

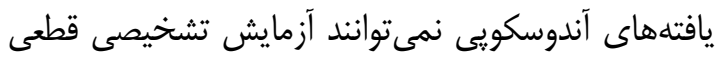

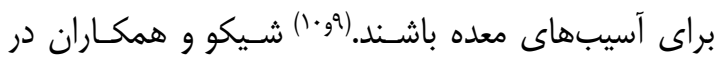

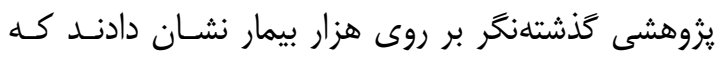

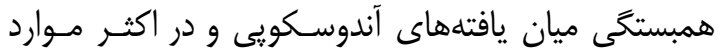

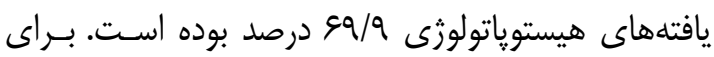

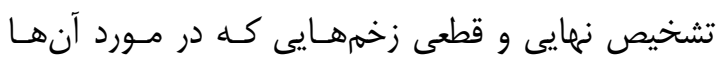

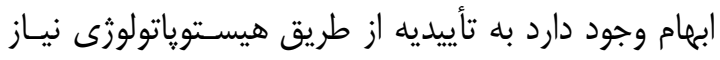

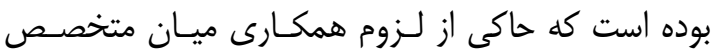

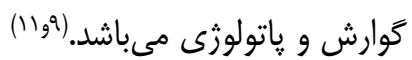
تركيب يافتههاى آندوسكويى و هيستوياتولوزى بـراى بـاى شناسايى زخهماى بيش سرطانى كه مستعد تبديل شـدن

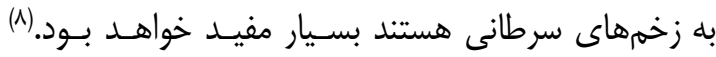

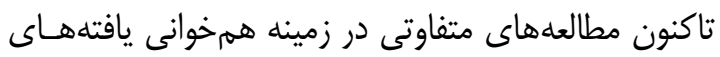
آندوسكويى و هيستوياتولوزيكى در بيويسى مئل معـده انجـام شده است كه نتايج متفاوتى را در اين زمينه نشان دادهاند.

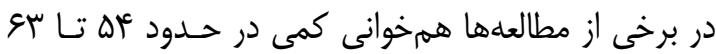

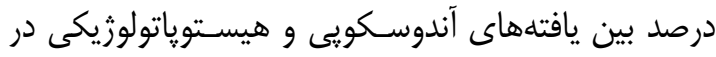

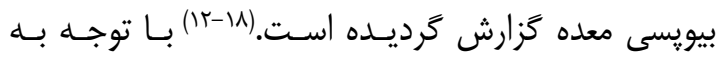

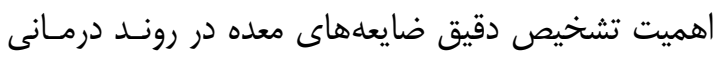

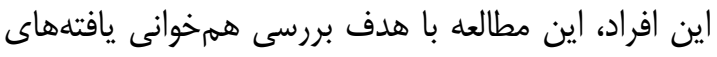

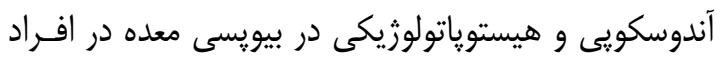
مراجعه كننده به بيمارستان فيروزگًر انجام شد.

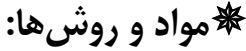

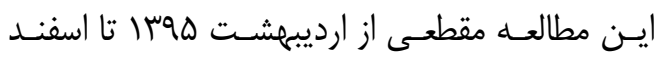




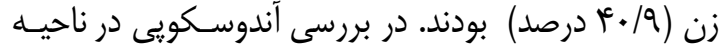

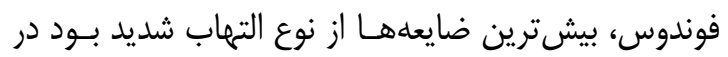

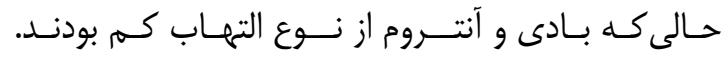

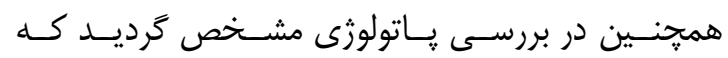

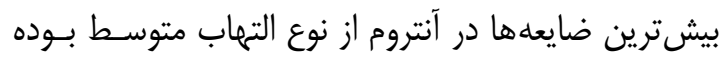
در حالى كه بادى و فوندوس از نوع التهاب كم مس باشـنـا.

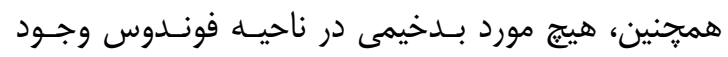

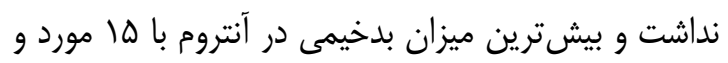

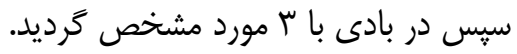

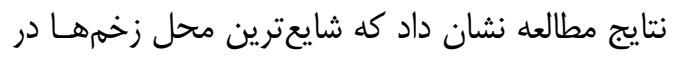

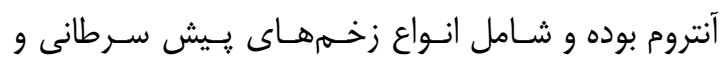

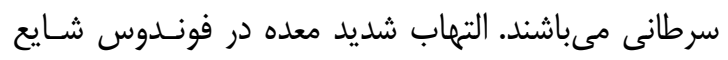

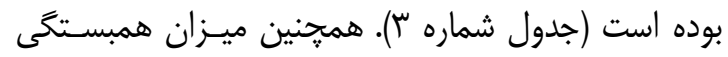

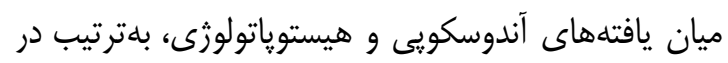

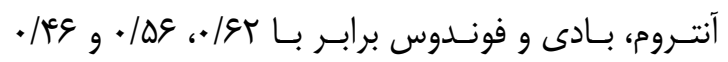

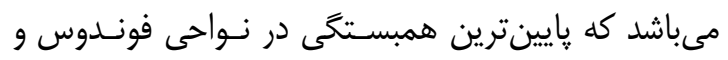

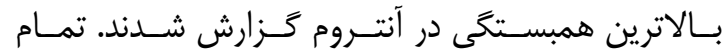

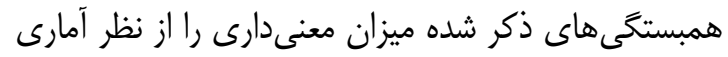

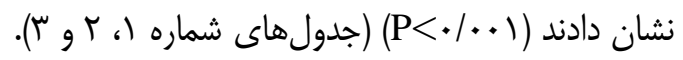

شدند. در اين مطالعـه اطلاعـات آندوسكويى از مشـاهده

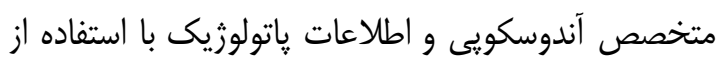

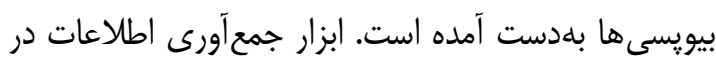

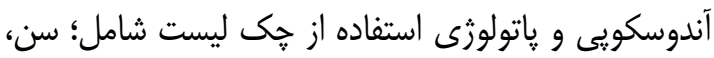

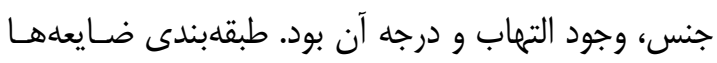

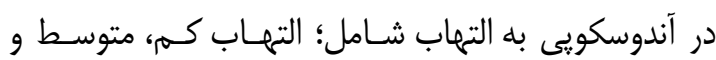

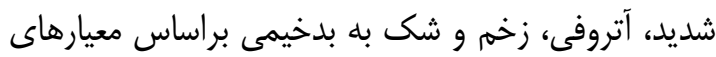

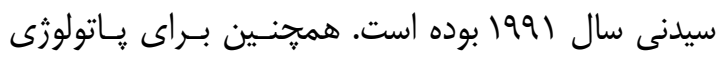

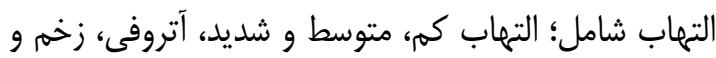

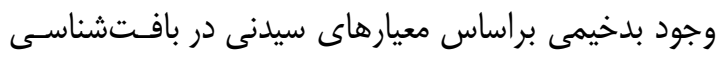
بوده است.

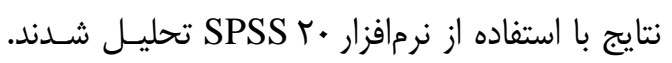

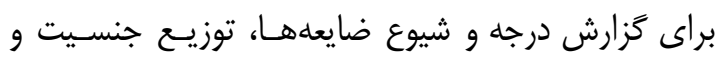
سن از روش تحليل توصيفى استفاده شد. سطح معنى دارى

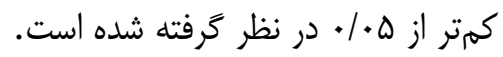

\section{每}

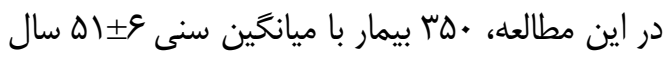

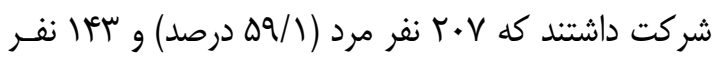

جدول ا - مقايسه نتايج آندوسكوبى و پِاتولوزى در ناحيه فوندوس معده

\begin{tabular}{|c|c|c|c|c|c|c|c|c|c|c|}
\hline \multirow{2}{*}{ سطح معنى دارى } & \multirow{2}{*}{ همبتتى } & \multicolumn{7}{|c|}{ باتولوزى } & \multirow{2}{*}{\multicolumn{2}{|c|}{ نتايج }} \\
\hline & & 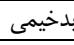 & زخ زخم & آتروفى & التهاب شديد & التهاب متوسط & التهاب كم & طبيعى & & \\
\hline \multirow{7}{*}{$>.1 . .1^{*}$} & \multirow{7}{*}{.$/ 4 \varphi^{2}$} & $\cdot$ & $\cdot$ & $\cdot$ & 1 & 9 & $r$ & ra1 & طبيعى & \multirow{7}{*}{ أندوسكويى } \\
\hline & & . & . & . & . & $r$ & $r$ & r & التهاب كم & \\
\hline & & . & . & . & . & $r$ & 1 & $r$ & التهاب متوسط & \\
\hline & & . & $\cdot$ & . & . & ז & $r$ & 1 & التهاب شديد & \\
\hline & & $\cdot$ & . & $\cdot$ & $\cdot$ & $\cdot$ & . & $\cdot$ & آتروفى & \\
\hline & & $\cdot$ & $\cdot$ & $\cdot$ & $\cdot$ & . & . & . & زخم & \\
\hline & & . & . & . & . & . & . & . & مشكوك به بدخيمى & \\
\hline
\end{tabular}

جدول ץ- مقايسه نتايج آندوسكويى و ياتولوزى در ناحيه بادى معده

\begin{tabular}{|c|c|c|c|c|c|c|c|c|c|c|}
\hline \multirow{2}{*}{ سطح معنى دارى } & \multirow{2}{*}{ همبستكى } & \multicolumn{7}{|c|}{ باتولوزى } & \multirow{2}{*}{\multicolumn{2}{|c|}{ نتايج }} \\
\hline & & 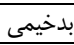 & زخم & آتروفى & التهاب شديد & التهاب متوسط & التهاب كم & طبيعى & & \\
\hline \multirow{7}{*}{$>+1 . .1^{*}$} & \multirow{7}{*}{$\cdot / \Delta s$} & $\cdot$ & $\cdot$ & 1 & $r$ & $r r$ & $\Delta F$ & IVF & طبيعى ل طبيع & \multirow{7}{*}{ أندوسكويى } \\
\hline & & $\cdot$ & $\cdot$ & $\cdot$ & 1 & $\pi$ & $\pi$ & 1. & التهاب كم. & \\
\hline & & $\cdot$ & 1 & $\cdot$ & . & $\Delta$ & 1 & $r$ & التهاب متوسط & \\
\hline & & $\cdot$ & $\cdot$ & $\cdot$ & $r$ & $\pi$ & $r$ & $\cdot$ & التهاب شديد & \\
\hline & & 1 & $\cdot$ & $F$ & $\cdot$ & $\cdot$ & $\cdot$ & $\cdot$ & آتروفى & \\
\hline & & 1 & F & . & . & $\cdot$ & . & $\cdot$ & pز & \\
\hline & & 1 & $r$ & . & . & . & . & . & مشكوك به بدخيمى & \\
\hline
\end{tabular}


جدول سـ- مقايسه نتايج آندوسكوبى و ياتولوزى در ناحيه آنتروم معده

\begin{tabular}{|c|c|c|c|c|c|c|c|c|c|c|}
\hline \multirow{2}{*}{ سطح معنىدارى } & \multirow{2}{*}{ همبستى } & \multicolumn{7}{|c|}{ ياتولوزى } & \multirow{2}{*}{\multicolumn{2}{|c|}{ نتايج }} \\
\hline & & بلذخيمى & زخم & آتروفى & التهاب شديد & التهاب متوسط & التهاب كم & طبيعى & & \\
\hline \multirow{7}{*}{$>\cdot / . .1 *$} & \multirow{7}{*}{. } & $\cdot$ & $\cdot$ & • & $\cdot$ & ir & $r$. & Iro & طبيعى & \multirow{7}{*}{ آندوسكويى } \\
\hline & & r & $\cdot$ & $\Delta$ & 1 & rt & rT & ז & التهاب كم & \\
\hline & & . & - & - & r & 1. & r & 1 & التهاب متوسط & \\
\hline & & 1 & te & te & 18 & 19 & r & - & التهاب شديد & \\
\hline & & . & 1 & - & r & . & r & - & آتروفى & \\
\hline & & 9 & 9 & - & r & - & - & - & زخم & \\
\hline & & $\Delta$ & r & . & $r$ & 1 & 1 & . & مشكوى به بدخيمى & \\
\hline
\end{tabular}

مختلف نشان دادهاند كه استفاده از دستكاههاى يِيشـرفته

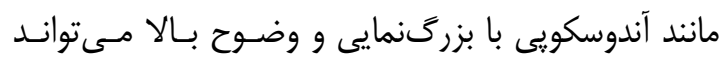

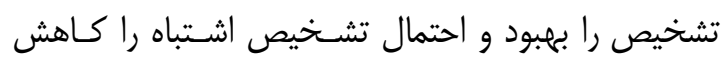
دهد.

هرجند فناورى در زمينه تصويربردارى بـا اسـتفاده از

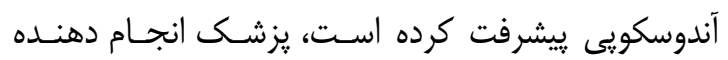

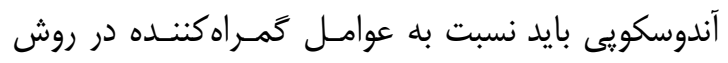
آكًاه باشند تا از تشخيص اشتباه انواع ضايعههاى بدخيم و

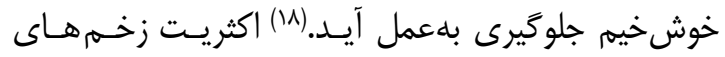

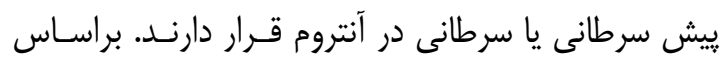

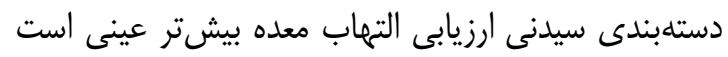

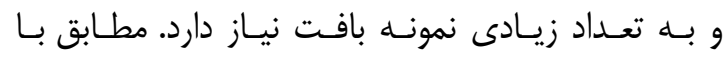

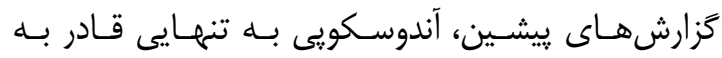

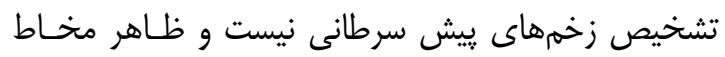

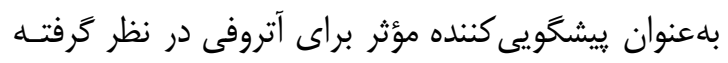
نمى شود. همجنين، كزارش شده است كه همبستخى ميان

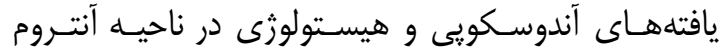

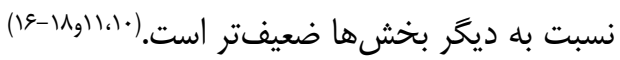

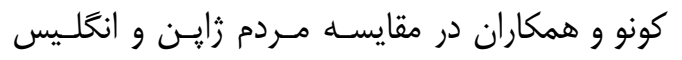

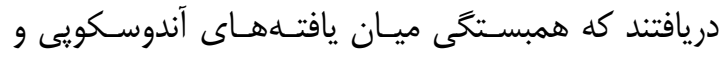
تحليل هيستولوزى براى تشـخيص آتروفى قابـل قبـول

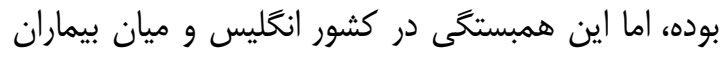
جوان برجستهتر بوده است. بلهور قابل توجهى با استفاده

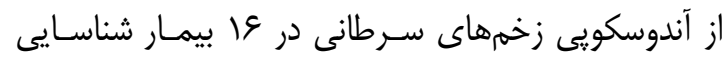

نتايج اين مطالعه در بررسى هـمخــوانى يافتـهـهـاى

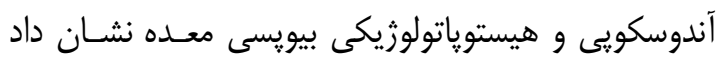

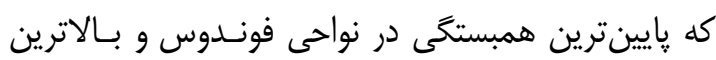

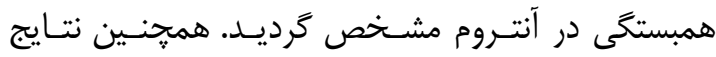

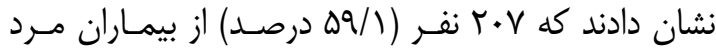

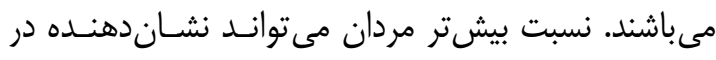

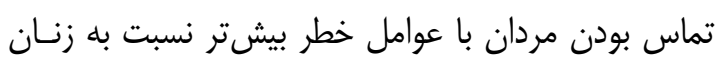

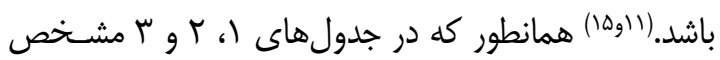

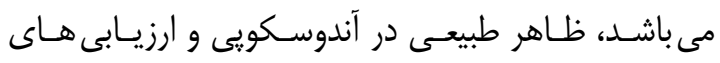
هيستولوزى در بيشتر موارد نتايجى مشابه را ارايه دادهاند.

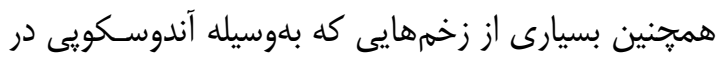

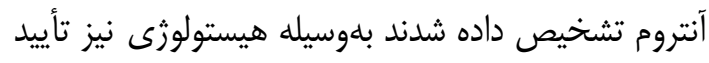

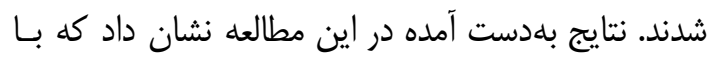
حركت از فوندوس به آنتروم تعداد زخهمهــاى تشـخـيص داده شده نيز افزايش يافتند.

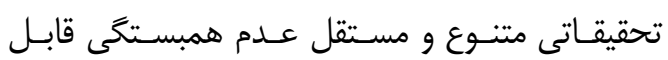

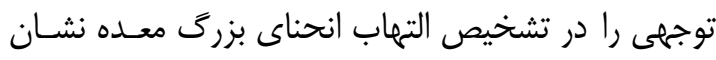

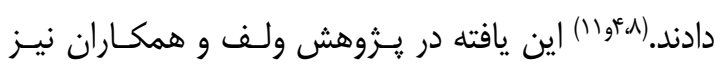

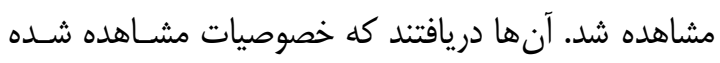

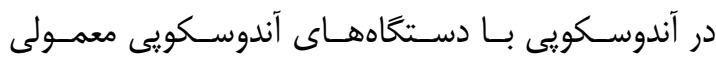

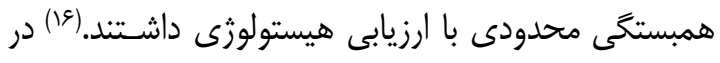

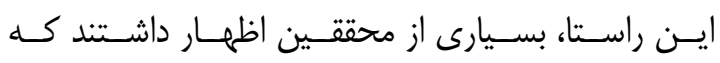

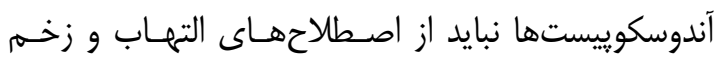

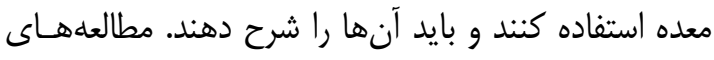


3. Leung WK, Wu MS, Kakugawa Y, Kim JJ, Yeoh KG, Goh KL, et al. Screening for gastric cancer in Asia: current evidence and practice. Lancet Oncol 2008; 9(3): 279-87. doi: 10.1016/S1470-2045(08)70072-X.

4. Carr NJ, Leadbetter $\mathrm{H}$, Marriott A. Correlation between the endoscopic and histologic diagnosis of gastritis. Ann Diagn Pathol 2012; 16(1): 13-5. doi: 10.1016/j. anndiagpath.2011.08.002.

5. Hajagamohammadi A, Sheikholslami H, Esmaeili R. Prevalence of Helicobacter Pylori infection in different endoscopic lesions of patients in Qazvin Bouali Sina hospital (2002). J Qazvin Univ Med Sci 2005; 9(3): 68-70. [In Persian]

6. Lim JH, Kim N, Lee HS, Choe G, Jo SY, Chon I, et al. Correlation between endoscopic and histological diagnoses of gastric intestinal metaplasia. Gut Liver 2013; 7(1): 41-50. doi: 10.5009/gnl.2013.7.1.41.

7. Sung JK. Diagnosis and management of gastric dysplasia. Korean J Intern Med 2016; 31(2): 201-9. doi: 10.3904/kjim.2016.021.

8. Ajayi AO, Ajayi EA, Solomon OA, Duduyemi B, Omonisi EA, Taiwo OJ. Corelation between the endoscopic and histologic diagnosis of gastritis at the Ekiti State university teaching hospital, Ado Ekiti, Nigeria. Inter J Internal Med 2015; 4(1): 913. doi: 10.5923/j.ijim. 20150401.02.

9. Sheiko MA, Feinstein JA, Capocelli KE, Kramer RE. The concordance of endoscopic and histologic findings of 1000 pediatric EGDs. Gastrointest Endosc 2015; 81(6): 1385-91. doi: 10.1016/j.gie.2014.09.010.

10. Nomura S, Ida K, Terao S, Adachi K, Kato $\mathrm{T}$, Watanabe $\mathrm{H}$, et al. Endoscopic diagnosis of gastric mucosal atrophy: multicenter prospective study. Dig Endosc 2014; 26(6): 709-19. doi: 10.1111/den.12286.
شدند كه از اين تعداد זا زخم در آنتروم قرار داشـتند. در

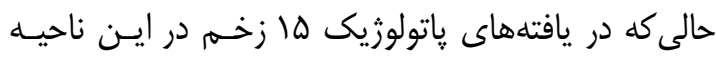

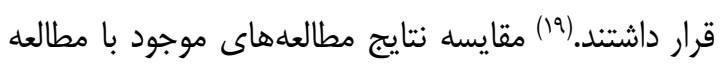

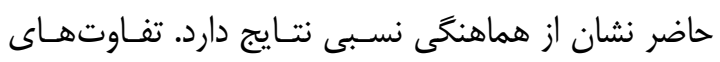

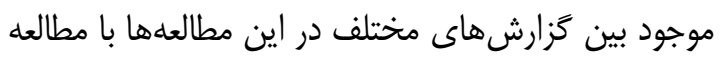

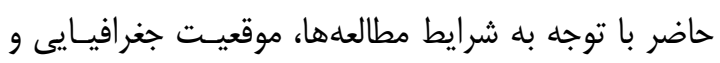

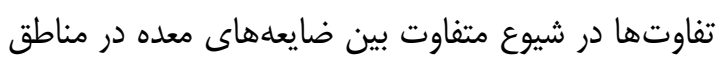

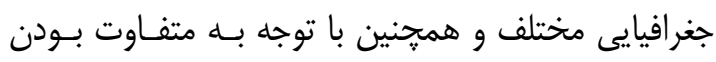
حجم نمونه استفاده شده در اين تحقيقات توجيه يذيذير است.

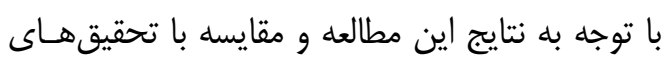

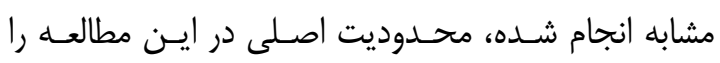

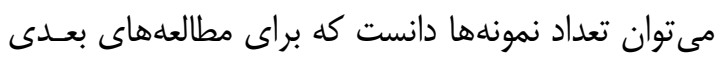
استفاده از حجم نمونه بيشتر توصيه مى شعود. همانطور كه كه

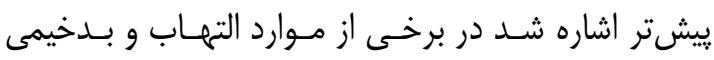

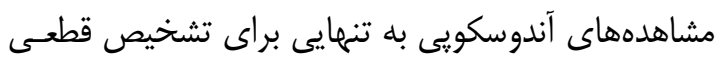

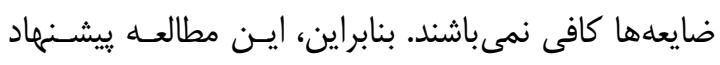

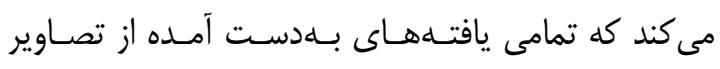
آندوسكويى بايد با تحليل هيستوياتولوزى تركيب شوند بافئد تاني در تشخيص دقيق به يزشى كمى كنند.

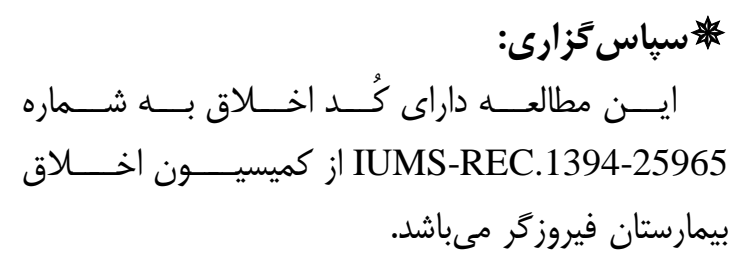

مراجع:

1. Matta J, Alex G, Cameron DJS, Chow CW, Hardikar W, Heine RG. Pediatric collagenous gastritis and colitis: a case series and review of the literature. J Pediatr Gastroenterol Nutr 2018; 67(3): 328-34. doi: 10.1097/MPG. 0000000000001975.

2. Rugge M, Fassan M, Graham DY. Epidemiology of gastric cancer. Gastric Cancer: Springer 2015; 12(3): 23-34. doi: 10. 1007/978-3-319-15826-6_2 
11. Sharma S, Makaju R, Dhakal R, Purbey B, Gurung RB, Shrestha R. Correlation between endoscopic and histopathological findings in gastric lesions. Kathmandu Univ Med J (KUMJ) 2015; 13(51): 216-9.

12. Kaur G, Raj SM. A study of the concordance between endoscopic gastritis and histological gastritis in an area with a low background prevalence of Helicobacter pylori infection. Singapore Med J 2002; 43(2): 0902.

13. Redéen S, Petersson F, Jönsson KA, Borch K. Relationship of gastroscopic features to histological findings in gastritis and Helicobacter pylori infection in a general population sample. Endoscopy 2003; 35(11): 946-50. doi: 10.1055/s-2003-43479.

14. Dixon MF, Genta RM, Yardley JH, Correa P. Classification and grading of gastritis: the updated Sydney system. Am J Surg Pathol 1996; 20(10): 1161-81.

15. Shennak MM, Tarawneh MS, Al-Sheikh TM. Upper gastrointestinal diseases in symptomatic Jordanians: a prospective endoscopic study. Ann Saudi Med 1997; 17(4): 471-4. doi: 10.5144/0256-4947.1997. 471.
16. Wolf E-M, Plieschnegger W, Geppert M, Wigginghaus B, Höss GM, Eherer A, et al . Changing prevalence patterns in endoscopic and histological diagnosis of gastritis? Data from a cross-sectional central european multicentre study. Dig Liver Dis 2014; 46(5): 412-8. doi: 10.1016/j.dld.2013.12.017.

17. Polydorides AD. Pathology and differential diagnosis of chronic, noninfectious gastritis. Semin Diagn Pathol 2014; 31(2): 114-123. doi: 10.1053/j.semdp. 2014.02.008

18. Mahmuda S, Bashar MF, Yesmin N, Khatun MA. Correlation between histopathological and endoscopic findings of stomach growth. Mymensingh Med J 2016; 25(1): 138-40.

19. Kono S, Gotoda T, Yoshida S, Oda I, Kondo H, Gatta L, et al. Can endoscopic atrophy predict histological atrophy? Historical study in United Kingdom and Japan. World J Gastroenterol 2015; 21(46): 13113-23. doi: 10.3748/wjg.v21.i46.13113. 